\title{
Dynamic testing of large scale fibrecrete panels
}

\author{
E. Villaescusa Western Australian School of Mines, Curtin University/CRC Mining, Australia
}

A.G. Thompson Western Australian School of Mines, Curtin University/CRC Mining, Australia

J.R. Player Western Australian School of Mines, Curtin University/CRC Mining, Australia

\begin{abstract}
The Western Australian School of Mines (WASM) has developed a state-of-the-art facility for the dynamic testing of full scale fibrecrete panels. A large scale punch test method has been developed to evaluate various mix designs at different curing times. The fibrecrete is sprayed on to a large sandstone or granite substrate containing an isolated $500 \mathrm{~mm}$ disc that is centrally located and used to simulate instability. The test sample is placed on to the sample frame and restrained on all sides. The disc is dynamically displaced and instruments measure the dynamic displacement and the load being applied to the sample through the loading disc. The force-displacement properties have been used to determine the dynamic energy absorbing capability of fibrecrete systems.
\end{abstract}

\section{Introduction}

Shotcrete is a surface support technique in which a specially mixed concrete is sprayed at high speed on to rock excavation surfaces to improve rock mass integrity and, therefore, resistance to geological structure or stress related failures. The benefits of using shotcrete compared with other ground support schemes have been demonstrated particularly where rock masses are of poor quality, have short stand-up times and are easily disturbed while attempting to scale or to drill boreholes for installation of reinforcement and mesh restraint. Wet mix shotcrete is now widely accepted in mines throughout the world, particularly those prone to violent rock failure due to major stress increases and minor stress decreases induced by mining.

\section{Support mechanisms}

Studies by Holmgren $(1976,2001)$ and Fernandez-Delgado et al. (1976) concluded that adhesion loss and flexure are the main modes of shotcrete failure. A further review of shotcrete capacity in blocky ground under static conditions conducted by Barrett and McCreath (1995) identified six failure mechanisms, namely, adhesion loss, direct shear, flexural failure, punching shear, compressive and tensile failure (Figure 1). Such failure mechanisms are generally not well understood and further research is required to understand the complexities of the rock-shotcrete interaction (Morton et al., 2009).

\section{$3 \quad$ Shotcrete reaction to transverse loading}

Rockbolt plates and shotcrete in direct contact with rock surfaces can provide confinement and immediate resistance to movement. This is different from straps and mesh which are usually only in contact with the rock at the positions of restraint and therefore allow rock movement (in some cases very significant) before providing restraint against further movement. For this reason, mesh alone may not be suitable for control of rock masses susceptible to violent failure due to overstressing. When shotcrete does not prevent rock failure, the energy absorbed is accompanied by a loss in the intimate contact with the rock and cracking to form 'slabs' of shotcrete (Figure 2). The crack widths may exceed the length of the any internal fibre reinforcement and therefore mesh is the only way of retaining the slabs of shotcrete that are not held directly by the reinforcing elements. 


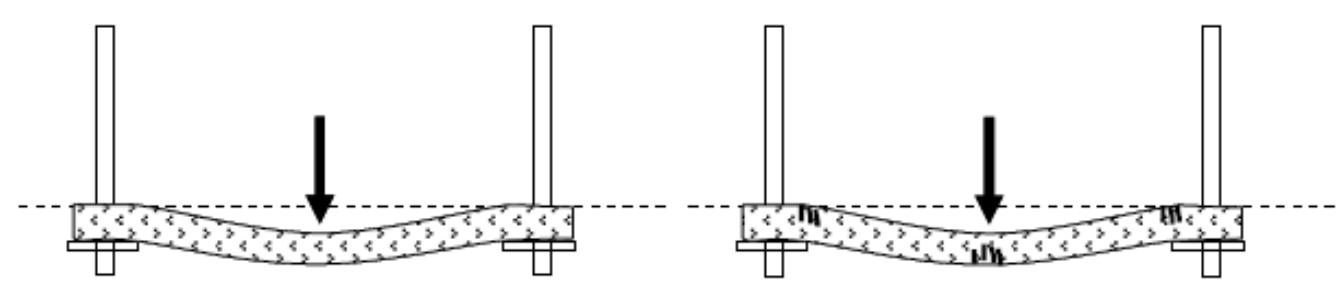

Adhesion Loss

Flexural Failure

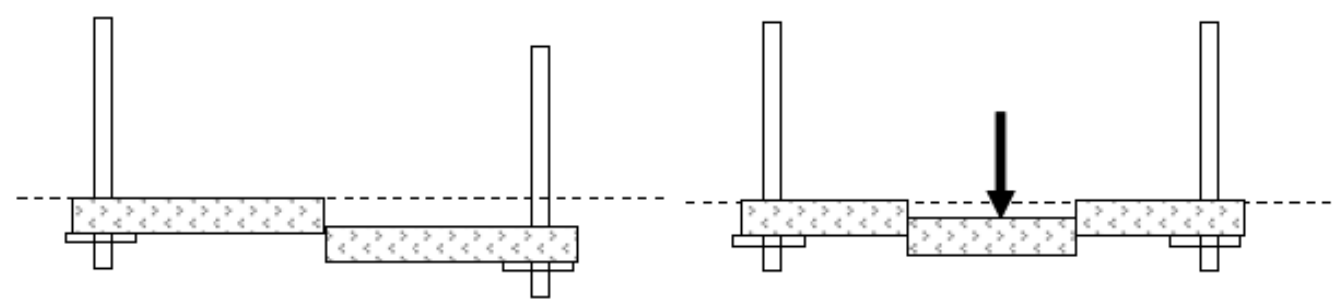

Direct Shear Failure

Punching Shear Failure

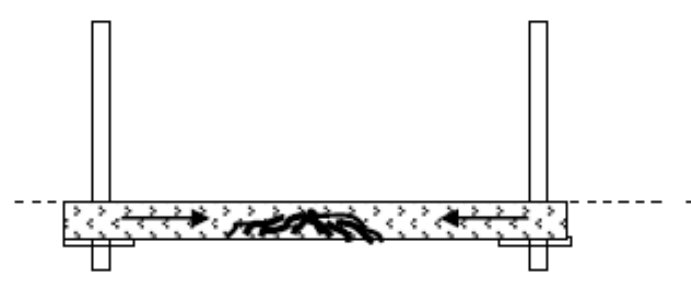

Compressive Failure

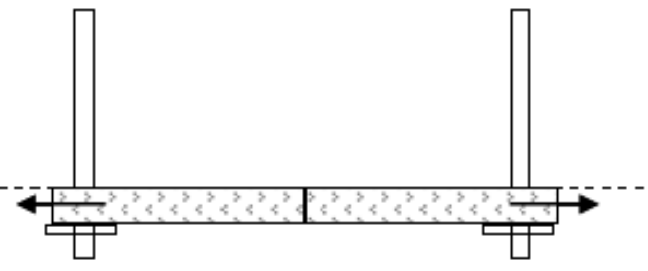

Tensile Failure

Figure 1 Shotcrete failure mechanisms (after Barrett and McCreath, 1995)

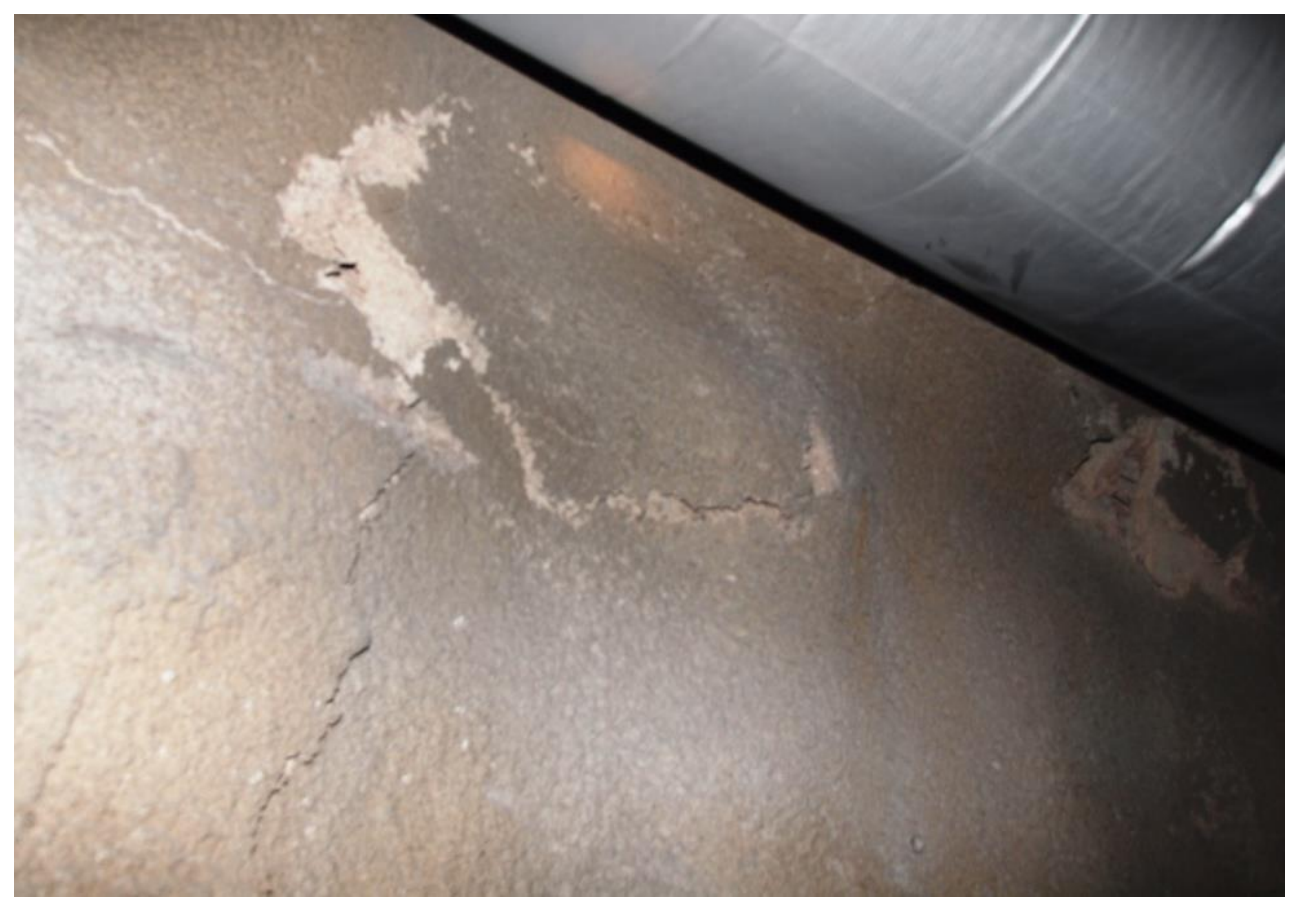

Figure 2 Unstable slabs of fibrecrete 


\section{$4 \quad$ Shotcrete reaction in tension}

Shotcrete may also act as a membrane in tension. The main disadvantage of shotcrete in tension is cracking at small strains/differential displacements. Although shotcrete performance is improved through the addition of steel or polypropylene fibres, the tensile strength is a function of how well the fibres transfer load across cracks (Figure 3). This depends on the number of fibres, the strength of the fibres, their orientation and the load transfer between the fibre and the shotcrete matrix.

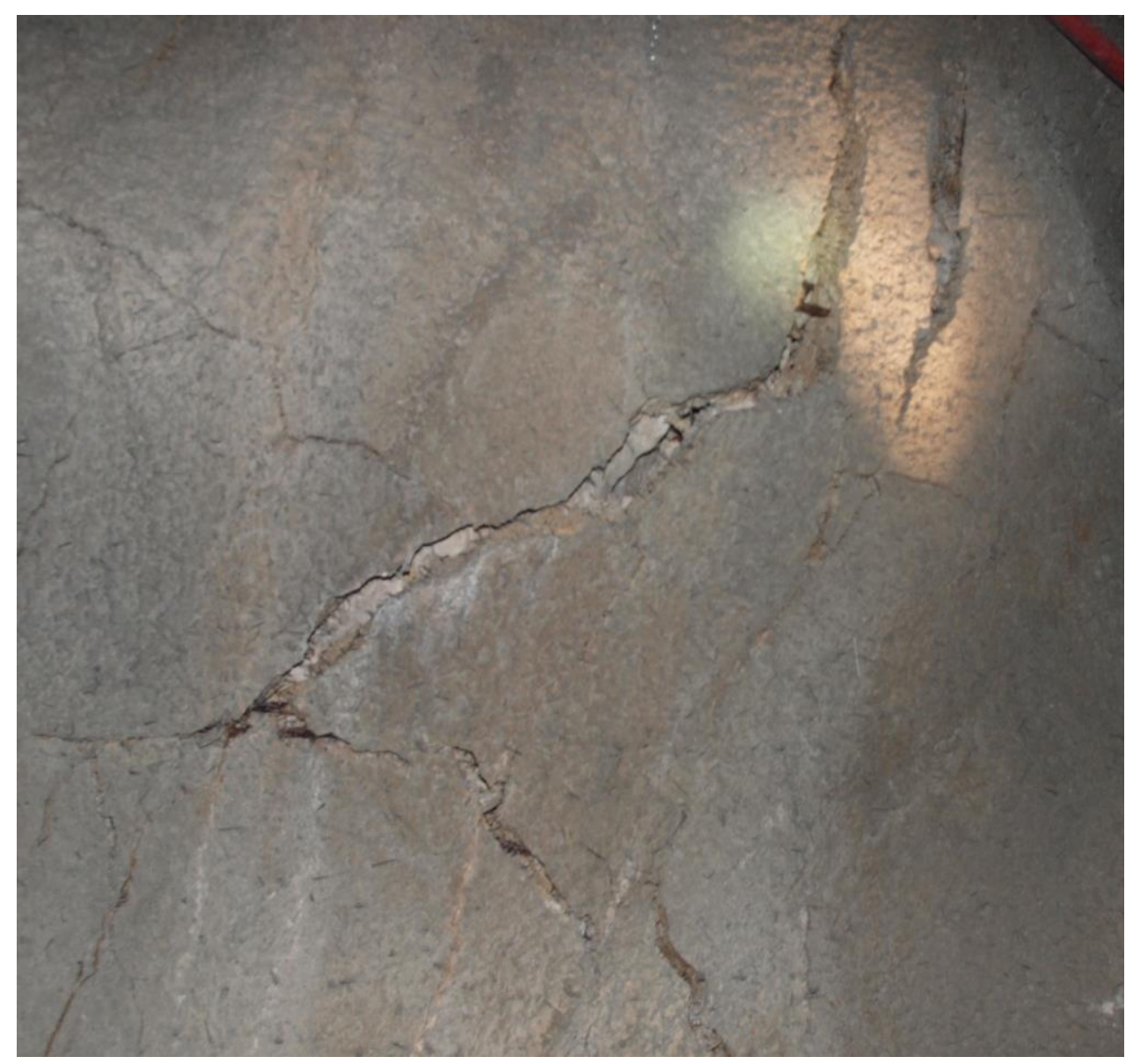

Figure 3 Shotcrete tensile crack opening exceeding the fibre length

Support systems designed to be efficient when loaded in tension have poor performance when loaded in compression. Straps and mesh tend to buckle when loaded in compression. A thin skin will have negligible strength and stiffness when compared with the rock with which it is in contact. Shotcrete-based products have appropriate properties for membrane action in compression in terms of both strength and stiffness. Plain shotcrete is susceptible to cracking due to both shrinkage and any distortion caused by rock movements. The resistance of shotcrete to cracking is improved by the addition to the mix of either steel or polypropylene fibres, or when used in conjunction with mesh. In addition to transverse loading, rock movements may also cause distortion in the plane of the support. These distortions produce shear forces which may in turn cause shear or tension cracks (Figure 4). Mesh or shotcrete reinforced with either fibres or mesh can sustain in-plane distortion. 


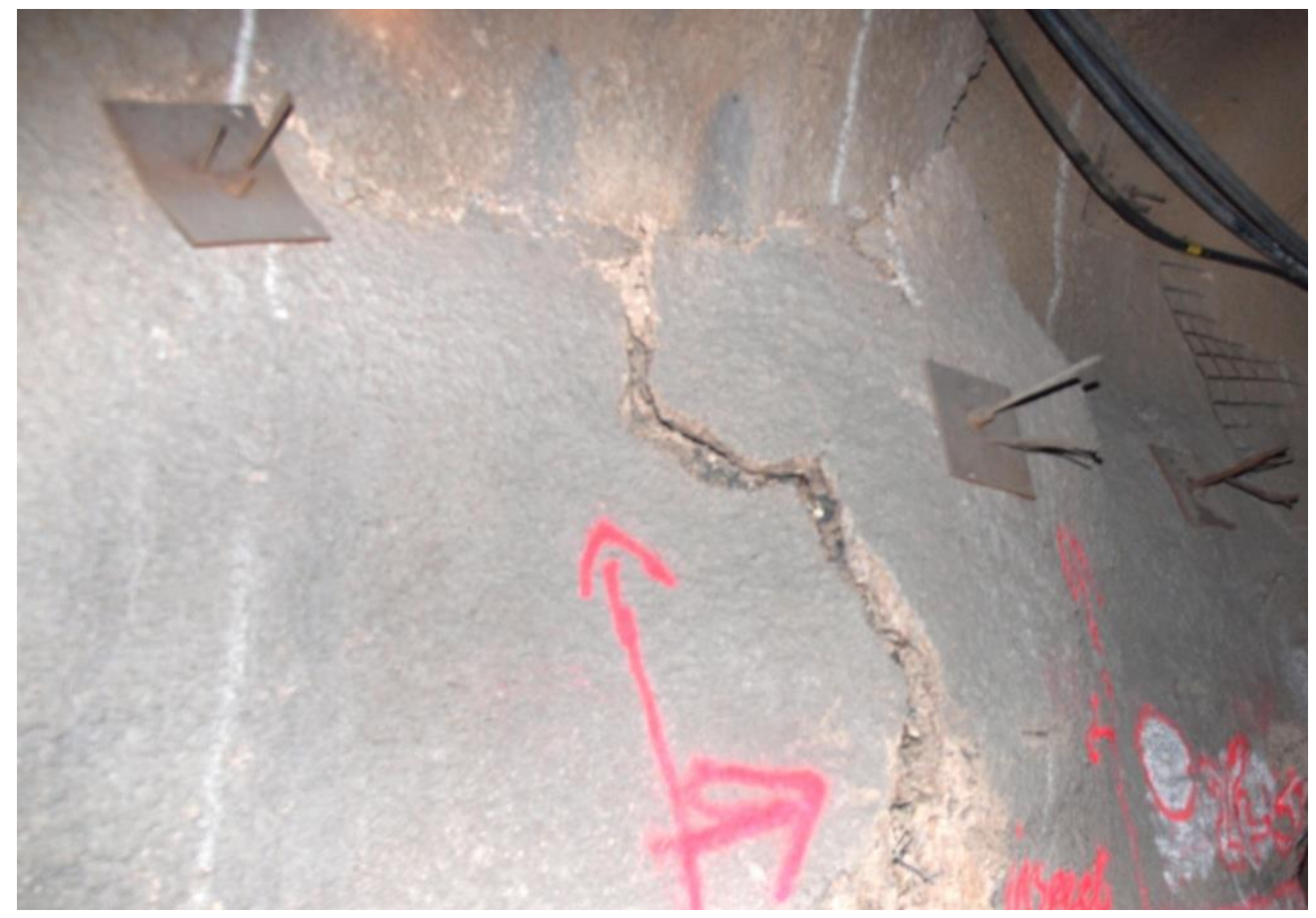

Figure 4 Shotcrete failure due to movement at an excavation wall

\section{$5 \quad$ Shotcrete toughness}

Toughness is defined as the ability of a support system to absorb energy and to deform plastically before failing. Toughness is used to assess the support system where the transient forces immediately after failure would be sufficient to cause support failure if the system did not deform until the rock force demand reduces to an acceptable level. Figure 5 shows some conceptual force-displacement responses for various configurations or mesh and shotcrete. The energy absorption can be determined by calculating the area under the force-displacement response curve. Determining energy at an arbitrary displacement is not indicative of the energy capacity of shotcrete. In order to effectively assess the energy absorption capacity, the cumulative energy absorption variation with central displacement should be considered.

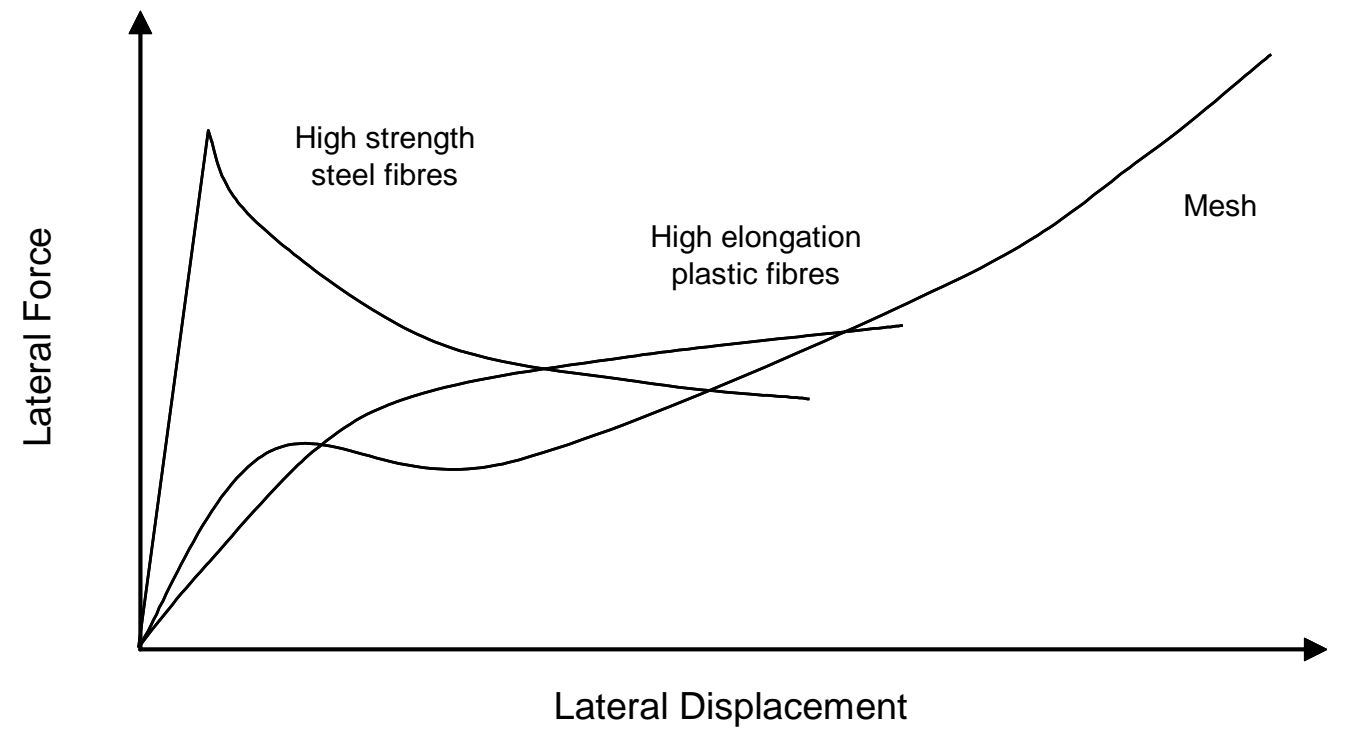

Figure 5 Conceptual force-displacement responses of laterally loaded surface support systems 


\section{6}

\section{Dynamic testing}

The results presented here have been obtained using the WASM Dynamic Testing Facility for ground support elements (Player et al., 2008; Morton, 2009). This facility consists of two steel frames, a lower frame used to support the shotcrete sample and an upper frame used to provide a reaction to loading. Samples are loaded using the momentum transfer concept (Player et al., 2004; Player, 2012). The upper frame is bolted to a drop beam while a $1.3 \mathrm{~m}$ square sample is supported by the lower frame that is bolted to the upper frame.

The fibrecrete panel is sprayed on to a large sandstone or granite substrate containing an isolated $500 \mathrm{~mm}$ disc that is centrally located and used to simulate instability (Figure 6). The test sample is restrained on all sides between the lower and upper frames. A loading mass is placed into the centre of the shotcrete panel. The drop beam and attached assembly are dropped from a specific height to generate dynamic loading on the sample. Sophisticated instrumentation, a high speed digital video camera, data logger and computer are used to record the test data. Data acquisition is undertaken at 25,000 samples per second. Figure 7 shows details of the sample set up prior to dynamic testing at WASM. Computer software is used to control recording of data and their analysis.
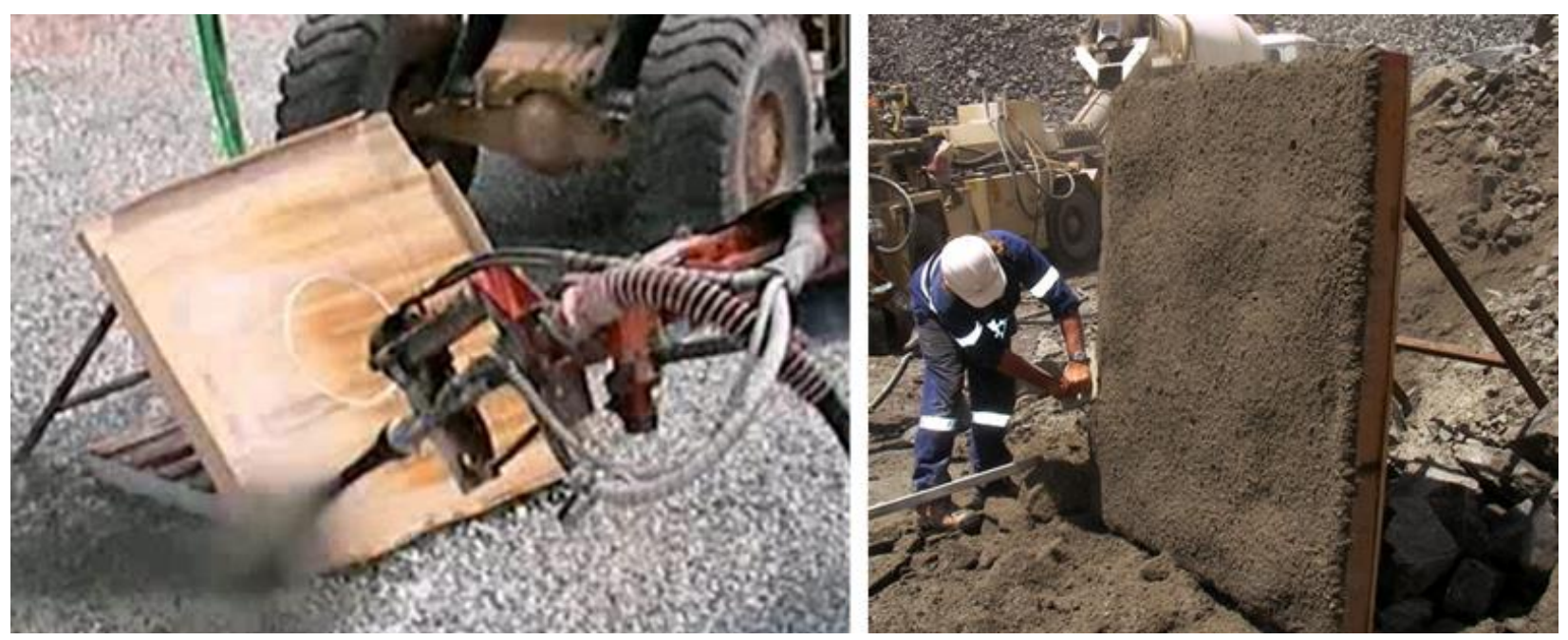

Figure 6 Details of shotcrete sample preparation
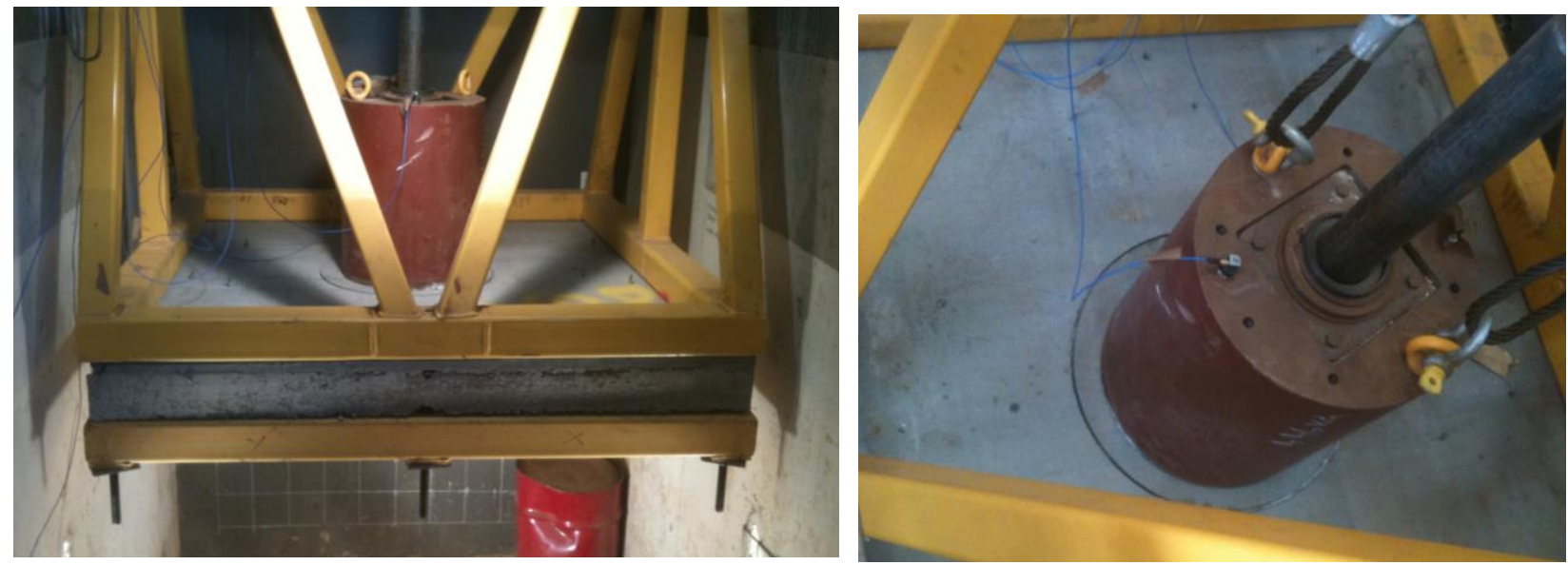

Figure 7 Details of shotcrete sample preparation and testing

\section{$7 \quad$ Typical results}

The sample and shotcrete layer specifications are summarised in Table 1. The mixes and fibres were those used by the mine sites at which the panels were sprayed. The shotcrete thickness variations are consistent 
with the difficulty of spraying to a nominal thickness of $75 \mathrm{~mm}$. The unavoidable variation in slab thickness also resulted in samples 1 and 2 only being supported on three sides.

The test specifications and summary of performance are given in Table 2. Sample 1 was subjected to two separate loadings. A loading mass of $446 \mathrm{~kg}$ was used in all tests.

Table 1 Shotcrete layer specifications

\begin{tabular}{ccccc}
\hline Sample & Slab Size $(\mathbf{W} \times \mathbf{L}) \mathbf{~ m}$ & $\begin{array}{c}\text { Shotcrete } \\
\text { Thickness }(\mathbf{m m})\end{array}$ & Fibre Type & Restraint \\
\hline 1 & $1.4 \times 1.5$ & 90 & Shogun & Three sides \\
2 & $1.4 \times 1.5$ & 102 & Shogun & Three sides \\
3 & $1.4 \times 1.5$ & 77 & Reoco Hookshot & Four sides \\
4 & $1.4 \times 1.5$ & 79 & Reoco Hookshot & Four sides \\
\hline
\end{tabular}

Table 2 Shotcrete dynamic test specifications and summary of performance

\begin{tabular}{ccccccc}
\hline Test & $\begin{array}{c}\text { Age } \\
\text { (days) }\end{array}$ & $\begin{array}{c}\text { Impact } \\
\text { Velocity } \\
(\mathbf{m} / \mathbf{s})\end{array}$ & $\begin{array}{c}\text { Energy } \\
\text { Input (kJ)* }\end{array}$ & $\begin{array}{c}\text { Peak } \\
\text { Force } \\
(\mathbf{k N})\end{array}$ & $\begin{array}{c}\text { Energy } \\
\text { Absorbed } \\
(\mathbf{k J})\end{array}$ & $\begin{array}{c}\text { Failure } \\
\text { Mechanism }\end{array}$ \\
\hline 1A & 25 & 3.3 & 2.4 & 17.5 & 0.01 & Bending/cracking \\
1B & 25 & 4.5 & 4.4 & 93 & 1.8 & Bending/cracking \\
2 & 32 & 5.7 & 7.2 & 96 & 3.5 & Bending/cracking \\
3 & 11 & 3.3 & 2.4 & - & - & Punch through \\
4 & 29 & 3.3 & 2.4 & - & - & Punch through \\
\hline
\end{tabular}

Samples 1 and 2, although severely cracked and deformed, did not fail completely. Photos showing some typical crack patterns are given in Figure 8 and Figure 9. These crack patterns have some similarities to those expected from yield line theory for centrally loaded slabs that are supported on three edges.

On the other hand, testing on samples 3 and 4 resulted in complete penetration of the load through the shotcrete layer as shown in Figures 10 Figure 11, respectively. Note that for sample 3, incomplete circular failure at the boundary of the loading resulted in adhesion causing some failure of the sandstone layer. For sample 4, the shear failure through the shotcrete layer occurred after some cracking as shown in Figure 12. 


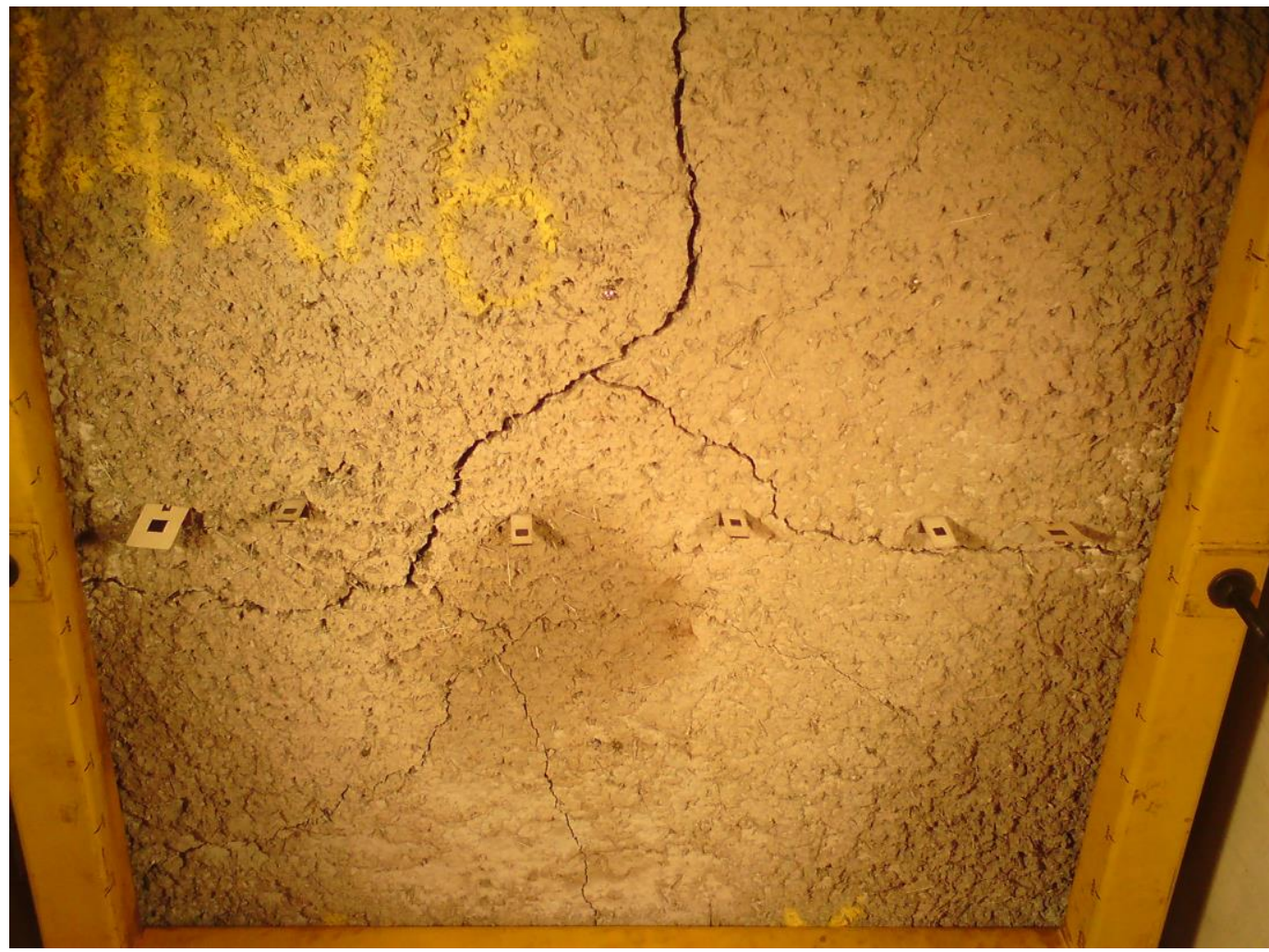

Figure 8 Crack pattern after second test on sample 1

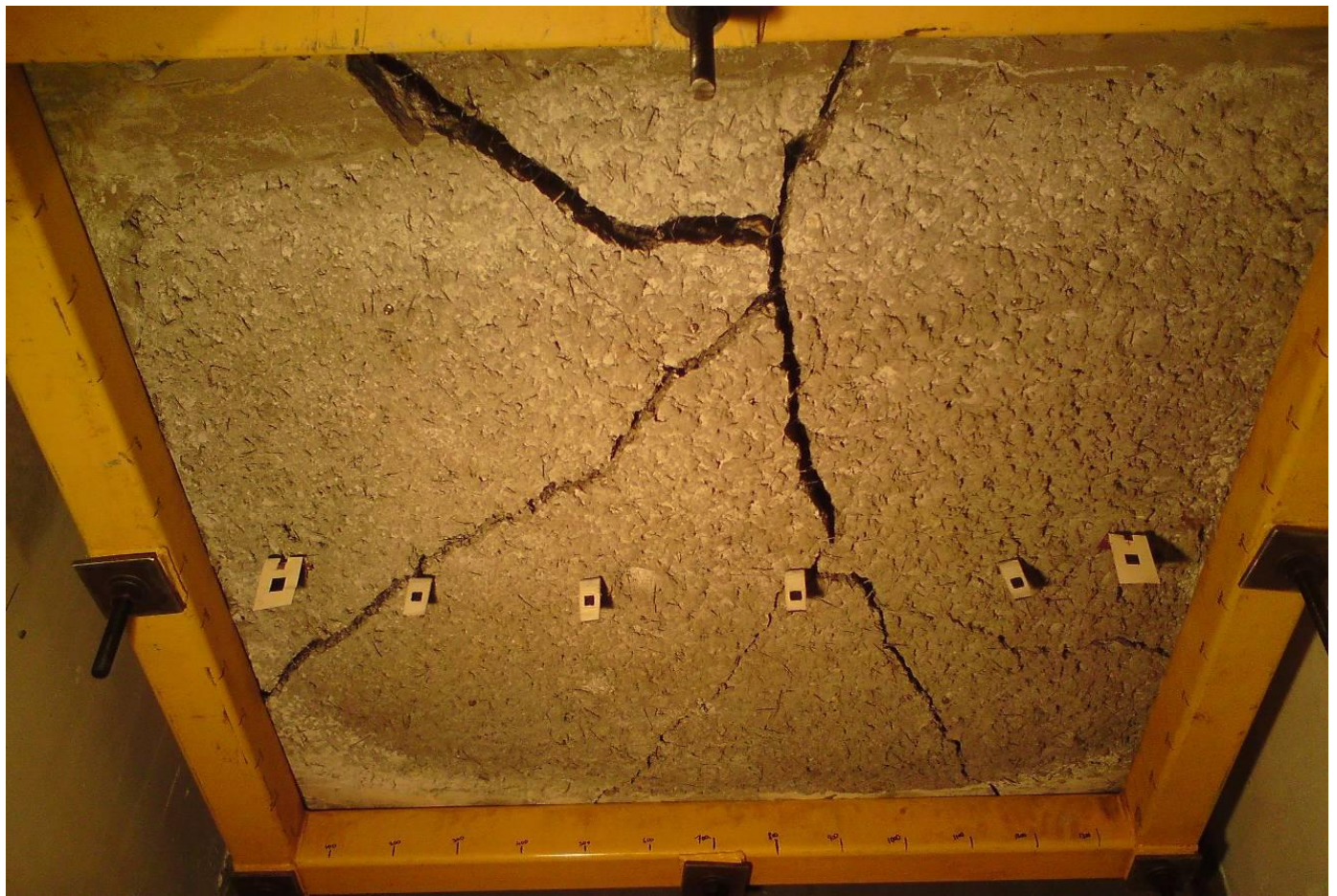

Figure 9 Crack pattern after test sample 2 


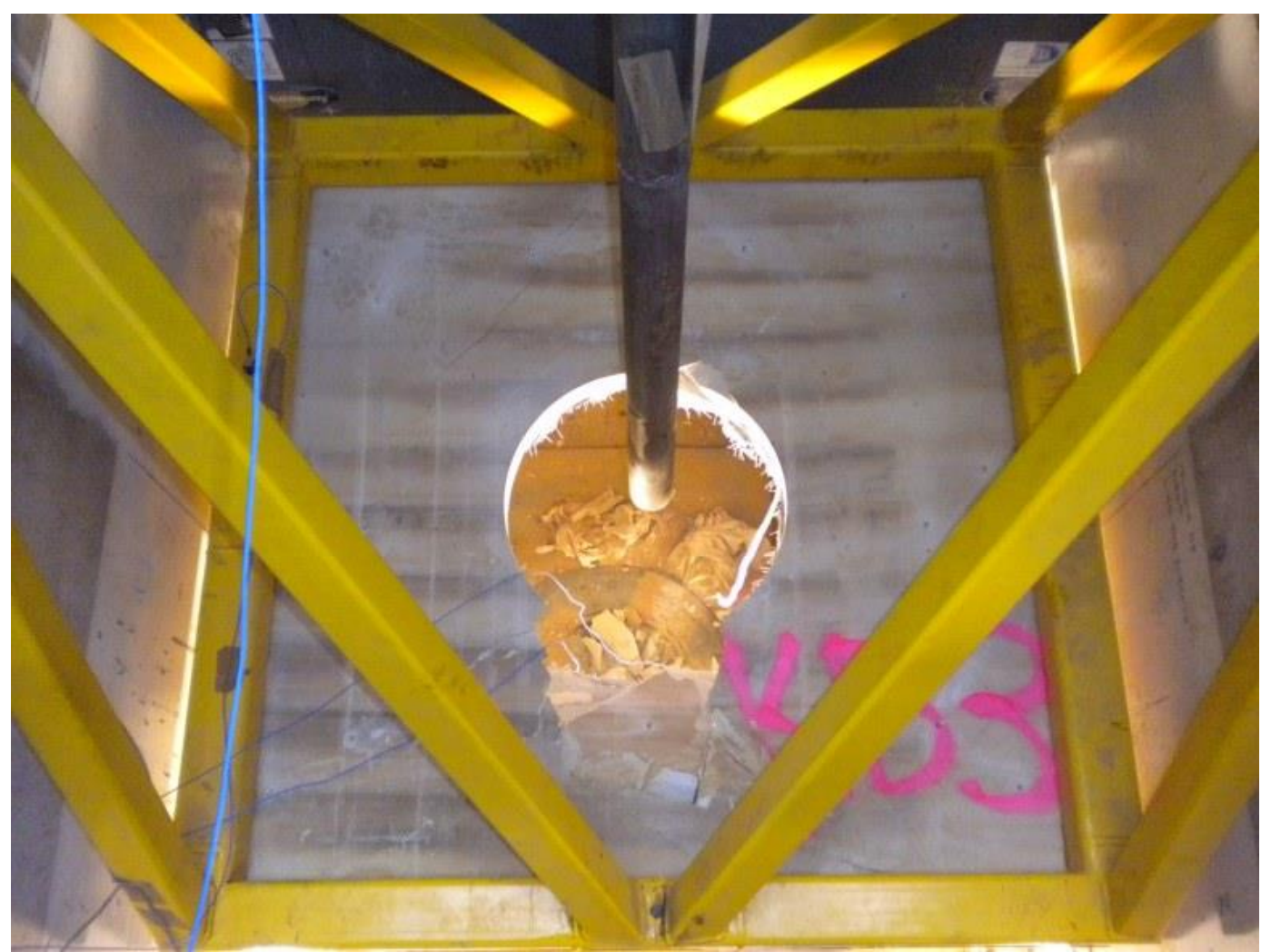

Figure 10 Punch through failure for sample 3

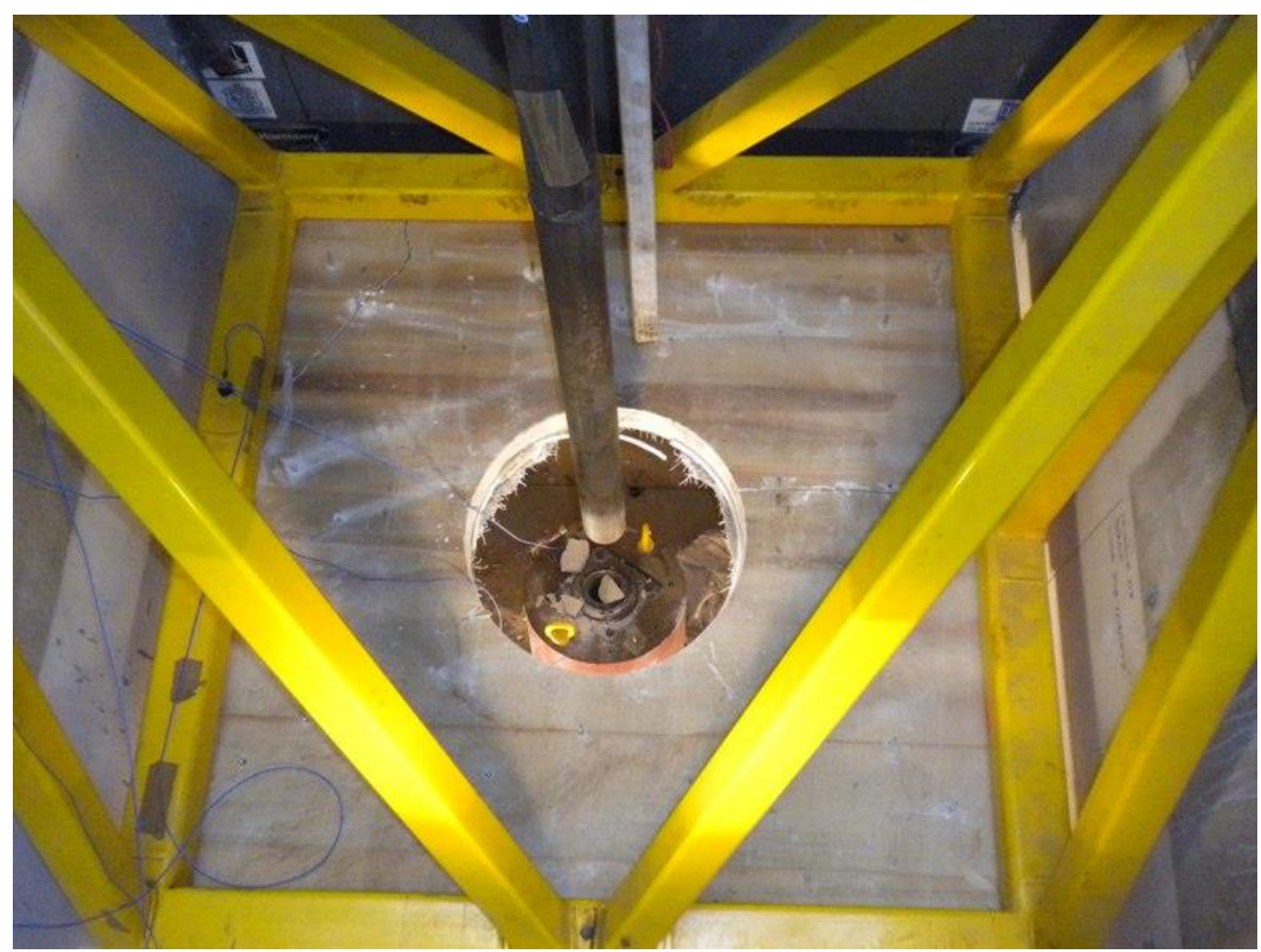

Figure 11 Punch through failure for sample 4 


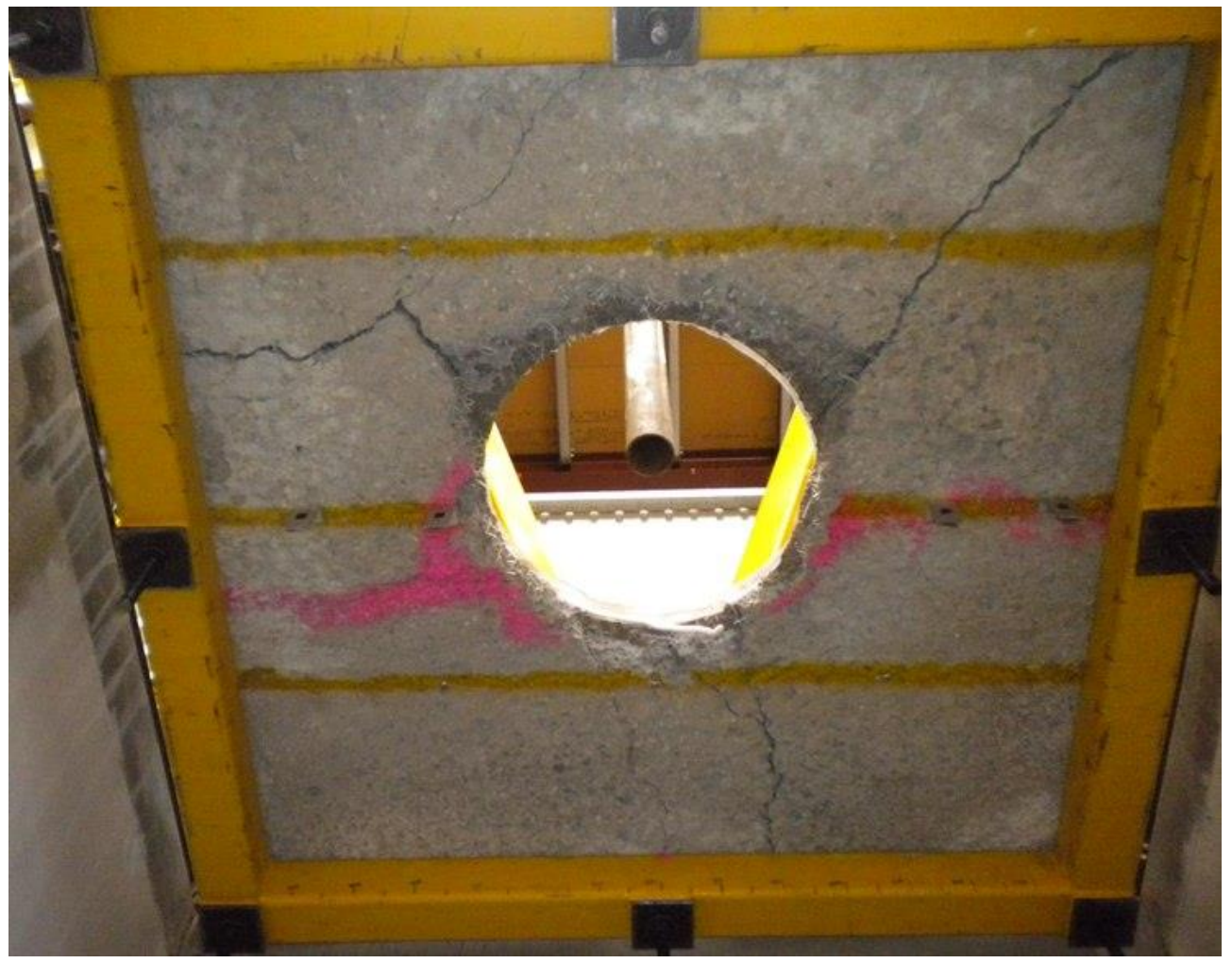

Figure 12 Cracking and punch through failure for sample 4

\section{$8 \quad$ Concluding remarks}

The Western Australian School of Mines has developed the WASM Dynamic Test Facility for testing and evaluation of all components of ground support; that is, reinforcement systems, mesh and shotcrete. The results for reinforcement systems and mesh have been reported in detail elsewhere (Player et al., 2004; 2008). Tests on fibre reinforced shotcrete panels have shown that cracking and punch through occur with only small magnitudes of energy being absorbed compared with the more ductile responses of reinforcement systems (in particular, those specially designed for high energy absorption) and mesh. Future testing will systematically investigate the effects resulting from different mix designs with fibre and mesh reinforcement for slabs with different thicknesses.

\section{Acknowledgement}

The financial assistance of the sponsoring mining companies, MERIWA and the CRC Mining in supporting the work of the WASM Rock Mechanics Group is gratefully acknowledged.

\section{References}

Barrett, S. and McCreath, D.R. (1995) Shotcrete support design in blocky ground: Towards a deterministic approach, Tunnelling and Underground Space Technology, Elsevier Science, London, Vol. 10, No. 1, pp. 79-89.

Fernandez-Delgado, G., Mahar, J. and Parker, H. (1976) Structural behaviour of thin shotcrete liners obtained from large scale tests, In Shotcrete for Ground Support, in Proceedings of the Engineering Foundation Conference, 4-8 October, Maryland, USA, ACl, Farmington Hills, pp. 399-442.

Holmgren, J. (2001) Shotcrete linings in hard rock, in Underground Mining Methods: Engineering Fundamentals and International Case Studies, W. Hustrulid and R. Bullock (eds), Colorado SME, Englewood, pp. 569-577.

Holmgren, J. (1976) Thin shotcrete layers subject to punch loads, Shotcrete for ground support, in Proceedings Engineering Foundation Conference, 4-8 October, Maryland, USA, ACl, Farmington Hills, pp. 443-459.

Morton, E.C. (2009) Static testing of large scale ground support panels, MSc Thesis, Curtin University, 250 p.

Morton, E.C., Villaescusa, E. and Thompson, A.G. (2009) Determination of energy absorption capabilities of large scale shotcrete panels, in Proceedings Shotcrete for Underground Support XI, F Amberg and K.F. Garshol (eds), Davos, Switzerland, Engineering Conferences International, New York, 20 p. 
Player, J.R. (2012) Dynamic testing of rock reinforcement systems, PhD Thesis, Curtin University, 260 p.

Player, J.R., Morton, E.C., Thompson, A.G. and Villaescusa, E. (2008) Static and dynamic testing of steel wire mesh for mining applications of rock surface support, in Proceedings Sixth International Symposium. on Ground Support in Mining and Civil Engineering Construction, T.R. Stacey and D. Malan (eds), 31 March-3 April, Cape Town, South Africa, The South African Institute of Mining and Metallurgy, Johannesburg, pp. 693-706.

Player, J.R., Villaescusa, E. and Thompson, A.G. (2004) Dynamic testing of rock reinforcement using the momentum transfer concept, in Proceedings Fifth International Symposium on Ground Support in Mining and Underground Construction, E. Villaescusa and Y. Potvin (eds), 28-30 September, Perth, Australia, Balkema, Rotterdam, pp. 327-339. 